\title{
Pengaruh kepuasan kerja dan budaya organisasi terhadap komitmen organisasi karyawan
}

\author{
Ellys Ellys \\ Universitas Tarumanagara, Jl. Tanjung Duren Utara No. 1, 11470, Indonesia \\ ellys.115160424@stu.untar.ac.id \\ Mei Ie* \\ Universitas Tarumanagara, Jl. Tanjung Duren Utara No. 1, 11470, Indonesia \\ meii@fe.untar.ac.id
}

*Penulis Korespondensi

Submitted: Oct 09, 2020; Reviewed: Oct 11, 2020; Accepted: Nov 02, 2020

\begin{abstract}
Job satisfaction is a feeling of pleasure or disappointed employees at work or the company and organizational culture are values or norms that are instilled by the company. These two important variables explain organizational commitment in the form of employee desires to maintain its membership in the company. The main purpose of this study is to find out the effect of job satisfaction and organizational culture on employee organizational commitment. The sample of this research was 50 respondents, who are employees in non-managerial positions. Sampling was done by nonprobability sampling with purposive sampling. The data analysis method used by researchers was PLS-SEM with bootstrapping method. The results of this study indicated that job satisfaction has a positive effect on organizational commitment and organizational culture has a positive effect on organizational commitment.
\end{abstract}

Keywords: job satisfaction; organizational commitment; organizational culture

Abstrak: Kepuasan kerja merupakan perasaan senang atau kecewa karyawan pada pekerjaan atau perusahaan dan budaya organisasi merupakan nilai atau norma yang ditanamkan oleh perusahaan. Kedua variabel penting tersebut menjelaskan komitmen organisasi yang berupa keinginan karyawan untuk memertahankan keanggotaannya di perusahaan. Tujuan utama penelitian ini adalah untuk mengetahui pengaruh kepuasan kerja dan budaya organisasi terhadap komitmen organisasi karyawan. Sampel penelitian ini adalah 50 orang responden, yang merupakan para karyawan pada posisi non manajerial. Sampling yang dilakukan adalah non-probability sampling dengan purposive sampling. Metode analisis data yang digunakan oleh para peneliti adalah PLS-SEM dengan metode bootstrapping. Hasil-hasil penelitian ini menunjukkan bahwa kepuasan kerja berpengaruh positif terhadap komitmen organisasi dan budaya organisasi berpengaruh positif terhadap komitmen organisasi.

Kata kunci: budaya organisasi; kepuasan kerja; komitmen organisasi 


\section{PENDAHULUAN}

Perusahaan yang didirikan tanpa karyawan yang bekerja di dalamnya, maka sebaik apapun visi dan misi yang telah dibentuk tidak akan memberikan hasil yang berarti dan tidak akan berjalan maupun bergerak yang membuat gagalnya perusahaan mencapai tujuannya. Oleh karena itu, maka karyawan (Sumber Daya Manusia/ SDM) adalah faktor sangat dibutuhkan perusahaan. Sebagai kebutuhan, maka perusahaan wajib untuk memertahankan karyawan yang bekerja di dalamnya, yakni dengan memaksimalkan komitmen organisasi karyawan itu sendiri. Fauzia (2020) mengungkapkan survei kepuasan kerja yang dilakukan di New York, berkesimpulan bahwa bonus kinerja dan berbagai manfaat unik yang diberikan perusahaan akan meningkatkan nilai moral perusahaan dari sisi pandang karyawan yang bekerja di perusahaan tersebut.

Kepuasan kerja merupakan suasana psikologis dan perasaan seseorang yang bersifat relatif dalam memersepsikan pekerjaannya atau aspek-aspek yang terdapat dalam pekerjaan tersebut (Yanti \& Dahlan, 2017). Jika karyawan merasa bahwa hasil kerja mereka dihargai oleh pimpinan, diberikan fleksibilitas dalam melaksanakan tugas, diberikan motivasi dalam bekerja, serta selalu diberikan arahan dan bimbingan, maka kepuasan kerja karyawan akan tumbuh sehingga meningkatkan komitmen organisasi karyawan pada perusahaan. Kepuasan kerja merupakan faktor yang dibutuhkan dari karyawan oleh perusahaan. Karyawan, yang merasa puas pada pekerjaan mereka, akan meningkatkan produktivitasnya.

Faktor lain yang juga dapat memengaruhi komitmen organisasi seorang karyawan adalah budaya organisasi. Budaya organisasi merupakan sekumpulan nilai perusahaan yang ditetapkan dan dijunjung tinggi oleh semua anggota organisasi. Nilai-nilai tersebut meliputi tata cara berbicara, bertindak, dan cara berperilaku, serta hal-hal yang diacu untuk menemukan solusi pada masalah terkait organisasi dan karyawan. Organisasi yang memiliki budaya yang baik dan tertanam dalam diri karyawan, akan menjadi pedoman bagi karyawan dalam menjalankan tugasnya sehari-hari, dan hal tersebut memacu peningkatan komitmen karyawan terhadap organisasi tempat mereka bekerja (Yanti \& Dahlan, 2017).

Budaya organisasi yang positif merupakan semangat yang menjadi dasar penting dalam membangun moral bagi seluruh anggota organisasi. Robbins \& Judge (2015) menyatakan bahwa budaya organisasi yang kuat akan berdampak terhadap perilaku karyawan, yang secara langsung mengurangi tingkat turnover, membentuk jiwa kekompakan, loyalitas, dan memaksimalkan komitmen karyawan terhadap perusahaan. Studi yang dilakukan oleh ElKordy (2013) menemukan bahwa perusahaan yang menerapkan budaya organisasi yang inovatif dan suportif akan berpengaruh positif terhadap komitmen organisasi karyawannya. Adapun tujuan penelitian ini adalah untuk mengetahui pengaruh kepuasan kerja dan budaya organisasi terhadap komitmen organisasi karyawan.

Daniel \& Purwanti (2015) menyatakan bahwa komitmen organisasi merupakan kecenderungan karyawan untuk memihak pada tujuan dan sasaran organisasi, serta berniat untuk memertahankan keanggotaannya dalam organisasi. Kawiana, Dewi, Martini, \& Suardana (2018) menyatakan bahwa komitmen organisasi merujuk pada kondisi para karyawan mengidentifikasi dirinya pada tujuan organisasi dan keinginannya untuk memertahankan keanggotaan dalam organisasi. ElKordy (2013) menyatakan bahwa komitmen organisasi merujuk pada proses identifikasi dan keterlibatan karyawan di dalam organisasi tempat mereka bekerja.

Adapun menurut Daniel \& Purwanti (2015) terdapat tiga dimensi pada komitmen organisasi, yakni komitmen afektif (kondisi karyawan memertahankan keanggotaannya dalam suatu organisasi yang disebabkan oleh faktor perasaan atau emosional yang positif), jadi karyawan bertahan dalam suatu organisasi disebabkan karena keinginannya sendiri, yang dapat saja timbul dari adanya rasa nyaman berada dalam organisasi tersebut; komitmen berkelanjutan (kondisi karyawan memertahankan keanggotaannya dalam suatu organisasi yang disebabkan oleh faktor adanya kebutuhan dan telah memertimbangkan keuntungan dan kerugian jika tetap bertahan dalam organisasi tersebut); serta komitmen normatif (kondisi karyawan memertahankan keanggotaannya dalam suatu organisasi yang disebabkan oleh adanya suatu keharusan atau kewajiban maupun alasan moral yang timbul karena adanya pengorbanan dari perusahaan yang telah mengeluarkan biaya pelatihan dan sebagainya).

Daniel \& Purwanti (2015) menyatakan bahwa kepuasan kerja adalah kondisi emosional tertentu yang menyenangkan karyawan ketika melaksanakan tugas dan tanggung jawab mereka. ElKordy (2013) menyatakan bahwa kepuasan kerja adalah perasaan menyeluruh karyawan terhadap pekerjaan 
dan sikap terkait berbagai aspek yang terdapat dalam pekerjaan. Bellias \& Koustelios (2014) menyatakan bahwa kepuasan kerja adalah persepsi karyawan mengenai lingkungan kerja, hubungan antar kolega, peluang pendapatan, dan promosi jabatan. Vizano, Setiyani, \& Nawangsari (2018) menyatakan bahwa kepuasan kerja adalah persepsi karyawan terkait lingkungan kerja, hubungan dengan kolega, tujuan, dan strategi perusahaan, serta kriteria keberhasilan.

Menurut Prenana (2017), terdapat empat dimensi pada kepuasan kerja, yaitu: pekerjaan itu sendiri, penghargaan, hubungan antar-pribadi, dan sifat pekerjaan. Pekerjaan itu sendiri merupakan kesempatan karyawan untuk menggunakan segenap kemampuan yang mereka miliki untuk melaksanakan tugasnya, serta adanya variasi tugas, umpan balik, dan kebebasan yang terdapat dalam pekerjaan tersebut. Penghargaan meliputi kebijakan pemberian kompensasi dan promosi untuk menghargai kinerja karyawan. Hubungan antar-pribadi merupakan hubungan baik antara seorang karyawan dengan rekan kerja, atasan, maupun bawahan dalam organisasi. Sifat pekerjaan meliputi lingkungan kerja, kenyamanan, dan fasilitas yang terdapat pada organisasi, yang memungkinkan karyawan untuk melakukan pekerjaan dengan baik.

ElKordy (2013) menyatakan bahwa budaya organisasi adalah sistem yang dibentuk dalam organisasi dan diterima oleh kelompok tertentu pada waktu tertentu. Schein (2009) menyatakan bahwa budaya organisasional adalah suatu pola asumsi bersama yang dipelajari oleh sekelompok kandidat organisasi ketika memecahkan masalah yang diadaptasikan secara eksternal dan diintegrasikan secara internal. Kawiana dkk. (2018) mengemukakan bahwa budaya organisasi merupakan seperangkat norma dan nilai yang digunakan oleh organisasi untuk mengarahkan perilaku para anggota organisasinya.

Menurut Jalees \& Ghauri (2016), terdapat enam dimensi pada budaya organisasi, yakni: karakteristik dominan (gambaran keseluruhan pada karakteristik organisasi tersebut), kepemimpinan organisasi (cara atasan dalam memimpin organisasi), manajemen karyawan (pola yang menampilkan cara karyawan diperlakukan dan tampilan mengenai lingkungan kerja organisasi), ikatan organisasi (ikatan yang digunakan dalam menyatukan tiap-tiap anggota organisasi), penekanan strategis (bidangbidang yang digunakan untuk mendorong strategi organisasi), dan kriteria kesuksesan (penentuan bagaimana kesuksesan didefinisikan, dihargai, dan dirayakan).

Penelitian yang dilakukan oleh Jalees \& Ghauri (2016) mengemukakan adanya pengaruh yang positif dari kepuasan kerja terhadap komitmen organisasi karyawan yang bekerja pada universitas swasta di Pakistan. Kepuasan kerja mengacu pada peristiwa emosional karyawan sehari-hari terhadap situasi pekerjaan yang dihadapi, yang mana berpengaruh terhadap komitmen organisasi karyawan, karena karyawan yang merasa puas akan memertahankan keanggotaannya di dalam organisasi (Supeli \& Creed, 2016). Selain itu, Daniel \& Purwanti (2015) juga mengemukakan bahwa adanya pengaruh yang positif dari kepuasan kerja terhadap komitmen organisasi karyawan yang bekerja di universitas swasta di Tangerang. Kepuasan kerja ditunjukkan dengan adanya sikap yang positif dari para karyawan terhadap pekerjaan mereka, yang diungkapkan berdasarkan evaluasi karyawan pada situasi pekerjaan mereka saat ini, yang mana karyawan yang merasa puas cenderung beradaptasi dengan baik pada kondisi kerja dibandingkan yang tidak puas, sehingga membuat karyawan menyatukan dirinya dengan kondisi kerja di perusahaan (Umam, 2010). Lebih lanjut, penelitian yang dilakukan oleh ElKordy (2013) mengemukakan adanya pengaruh yang positif dari kepuasan kerja terhadap komitmen organisasi karyawan eksekutif yang terdaftar dalam program EMBA (Executive Master of Business Administration) dan karyawan lulusan fakultas perdagangan.

Penelitian Jalees \& Ghauri (2016) menemukan adanya pengaruh positif budaya organisasi terhadap komitmen organisasi karyawan yang bekerja pada universitas swasta di Pakistan. Budaya organisasi yang kuat berpengaruh terhadap organizational outcomes, seperti: kinerja yang baik, perilaku organisasi karyawan positif, kontrak psikologis antar kolega yang baik, serta tingkat absensi yang minim (Firuzjaeyan, Firuzaeyan \& Sadeghi, 2015). Budaya organisasi mengacu pada nilai-nilai dan norma yang dibentuk perusahaan, yang mana jika karyawan merasa cocok dengan nilai dan norma tersebut, mereka akan lebih melibatkan dirinya dalam organisasi serta memertahankan keanggotaannya dalam organisasi tersebut (Azadi, Farsani, Farsani, \& Aroufzad, 2013). Lebih lanjut, penelitian yang dilakukan oleh Kawiana dkk. (2018) menemukan bahwa terdapat pengaruh budaya organisasi secara positif dan signifikan terhadap komitmen organisasi karyawan Bank Perkreditan Rakyat (BPR) di Bali. Budaya organisasi yang baik dan sesuai dengan kondisi karyawan akan menurunkan angka turnover karyawan (Robbins \& Judge, 2015). Kemudian, apabila tujuan harmonis 
tercapai antara karyawan dengan organisasi dari segi budaya, maka karyawan akan menginternalisasi budaya tersebut, yang akan membangun komitmen organisasi karyawan yang lebih kuat (Kawiana dkk., 2018). Model penelitian dapat dilihat pada Gambar 1 berikut.

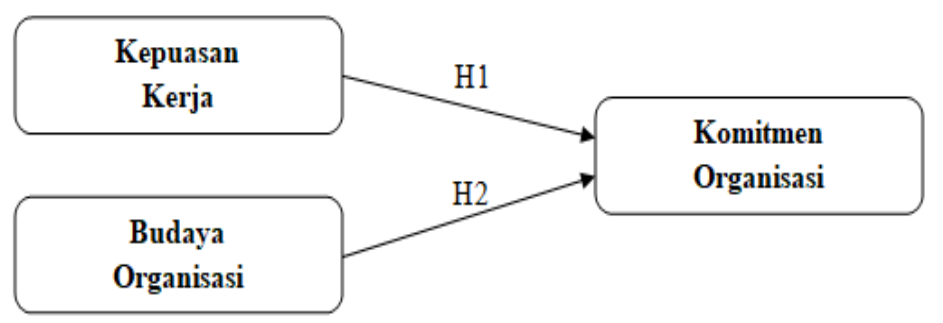

Gambar 1. Model penelitian

Sumber: Kerangka pemikiran peneliti

Berdasarkan definisi variabel dan kerangka pemikiran yang dibahas, dapat ditetapkan hipotesis penelitian sebagai berikut:

H1: Kepuasan kerja berpengaruh positif terhadap komitmen organisasi karyawan.

$\mathrm{H} 2$ : Budaya organisasi berpengaruh positif terhadap komitmen organisasi karyawan.

\section{METODE}

Desain penelitian ini adalah riset kuantitatif dengan pendekatan deskriptif, yang bertujuan untuk mendeskripsikan objek penelitian dan hasil penelitian. Sugiyono (2016) menyatakan bahwa pendekatan deskriptif merupakan pendekatan yang memiliki fungsi untuk memberikan deskripsi/ gambaran pada objek yang diteliti melalui data/ sampel yang telah terkumpul sebagaimana adanya dan tidak ada variabel yang dimanipulasi dalam penelitian.

Metode non-probability sampling dengan teknik purposive sampling digunakan dalam penelitian ini (Sekaran \& Bougie, 2013). Ukuran sampel dalam penelitian ini sebesar 50 orang responden karyawan non manajerial. Dari 50 orang responden penelitian tersebut, mayoritas yang berjenis kelamin wanita sebanyak 27 orang atau 54\% dan kemudian diikuti oleh pria sebanyak 23 orang atau 46\%. Mayoritas responden berusia 31-40 tahun sebanyak 30 orang atau 60\%. Mayoritas responden bermasa kerja di antara 1-3 tahun sebanyak 25 orang atau 50\%. Mayoritas responden menjabat pada divisi pemasaran sebanyak 17 orang atau 34\%. Mayoritas responden berpendidikan terakhir strata 1 (S1) sebanyak 31 orang atau $62 \%$.

Data penelitian ini dianalisis dengan menggunakan program software SmartPLS versi 3.3.2. Pertama, pengolahan dilakukan pada outer model untuk menguji validitas dan reliabilitas. Analisis validitas dilihat dari nilai outer loadings $>0,5$ dan nilai average variance extracted $>0,5$ (Hock \& Ringle, 2006). Kriteria nilai cross loadings adalah nilai outer loadings yang dihasilkan tiap indikator terhadap konstruk latennya harus lebih besar dibandingkan nilai outer loadings tiap indikator terhadap konstruk laten lainnya (Garson, 2016). Selanjutnya, analisis reliabilitas dilihat dari besarnya nilai pada cronbach alpha (Ghozali \& Latan, 2015), yang mana di atas 0,7 merupakan krtieria nilainya bahwa suatu data yang digunakan dapat diklaim memiliki reliabilitas.

Kedua, pengolahan dilakukan pada inner model untuk menguji hipotesis yang telah dihasilkan. Sebelum pengujian hipotesis, pertama dilakukan pengujian konstruk penelitian dengan melihat nilai Rsquare $\left(\mathrm{R}^{2}\right)$ dengan jika nilainya $1-0,67$ berarti terdapat pengaruh kuat atau substansial, jika antara 0,66 - 0,33 maka pengaruh yang terjadi adalah moderat atau sedang, dan jika nilai R-square berkisar antara 0,32-0,19 berarti terdapat pengaruh lemah (Hock \& Ringle, 2006). Untuk nilai R-square, jika nilainya $0,02-0,14$ berarti pengaruhnya lemah, $0,15-0,34$ berarti pengaruhnya sedang, dan di atas 0,35 berarti terdapat pengaruh yang kuat (Garson, 2016). Untuk nilai GoF (Goodness of Fit), jika nilainya sebesar 0,1 berarti kelayakan model kecil, nilai 0,25 berarti kelayakan model sedang, dan nilai 0,36 berarti kelayakan model besar (Garson, 2016). Selanjutnya pengujian hipotesis, untuk melihat prediksi yang terjadi positif atau negatif, dari coefficient (original sample) yang dihasilkan dan 
menggunakan $t$-statistics, yang jika nilainya $>1,645$ artinya hipotesis tidak ditolak dan jika nilai $\rho$ values $<0,05$ artinya hipotesis signifikan (Garson, 2016).

\section{HASIL DAN PEMBAHASAN}

Gambar 2 menjelaskan hasil uji validitas setiap variabel. Hasil uji validitas menunjukkan bahwa semua indikator yang digunakan untuk mengukur variabel dalam penelitian ini dinyatakan valid secara konvergen karena memiliki nilai outer loadings lebih besar dari 0,5. Selain itu, juga dinyatakan valid secara konvergen karena memiliki nilai average variance extracted (AVE) pada masing-masing variabelnya lebih besar dari 0,5 .

Pada nilai outer loadings yang dihasilkan tiap indikator terhadap konstruk latennya lebih besar dibandingkan nilai outer loadings tiap indikator terhadap konstruk laten lainnya, maka disimpulkan bahwa berdasarkan pengujian validitas diskriminan, variabel dan indikator yang digunakan adalah valid, yang beracuan pada nilai cross loadings.

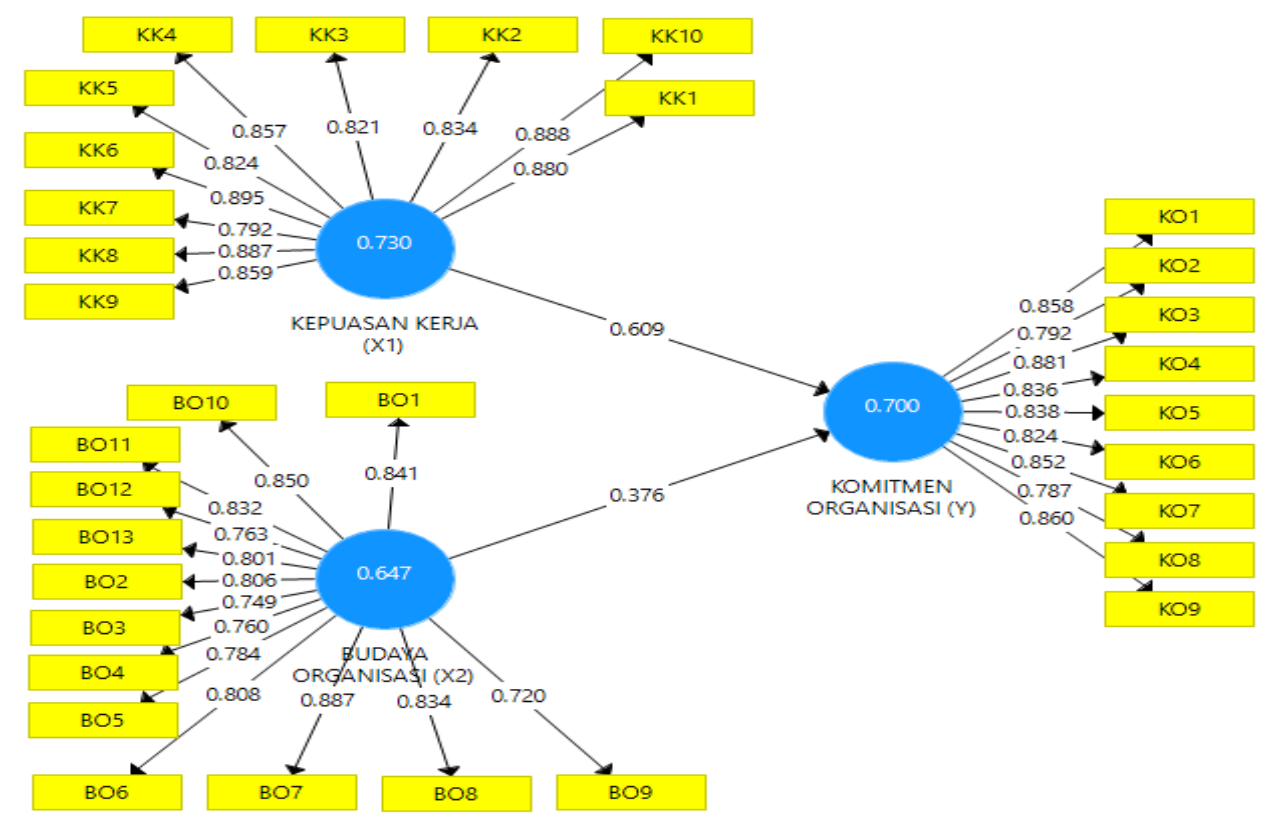

Gambar 2. Output smartPLS nilai outer loadings dan AVE

Sumber: Hasil pengolahan smartPLS (2020)

Tabel 1. Hasil uji reliabilitas pada nilai composite reliability dan cronbach's alpha

\begin{tabular}{lccc}
\hline \multicolumn{1}{c}{ Variabel } & Composite Reliability & Cronbach's Alpha & Keterangan \\
\hline Kepuasan kerja (X1) & 0,964 & 0,959 & Reliabel \\
\hline Budaya organisasi (X2) & 0,960 & 0,954 & Reliabel \\
\hline Komitmen organisasi (Y) & 0,955 & 0,946 & Reliabel \\
\hline
\end{tabular}

Sumber: Hasil pengolahan smartPLS (2020)

Hasil uji reliabilitas menunjukkan bahwa semua variabel yang digunakan dalam penelitian ini adalah reliabel karena memiliki nilai composite reliability dan cronbach's alpha yang lebih besar dari 0,7 . Oleh karena itu, dapat disimpulkan bahwa setiap indikator yang digunakan dalam penelitian ini adalah reliabel dalam mengukur variabel kepuasan kerja, budaya organisasi, dan komitmen organisasi.

Nilai R-square $\left(\mathrm{R}^{2}\right)$ yang dihasilkan sebesar 0,93 (bersifat kuat) pada variabel komitmen organisasi, sehingga dapat diartikan bahwa variabel kepuasan kerja dan budaya organisasi dapat menjelaskan variabel komitmen organisasi sebesar 93\%. Nilai q-square yang dihasilkan oleh konstruk penelitian ini sebesar 0,645. Angka tersebut mengandung arti bahwa model penelitian yang digunakan 
memiliki relevansi prediktif yang besar. Nilai dari hasil Uji GoF sebesar 0,6923. Hal tersebut mengandung arti bahwa tingkat kesesuaian atau kelayakan pada model penelitian ini kuat.

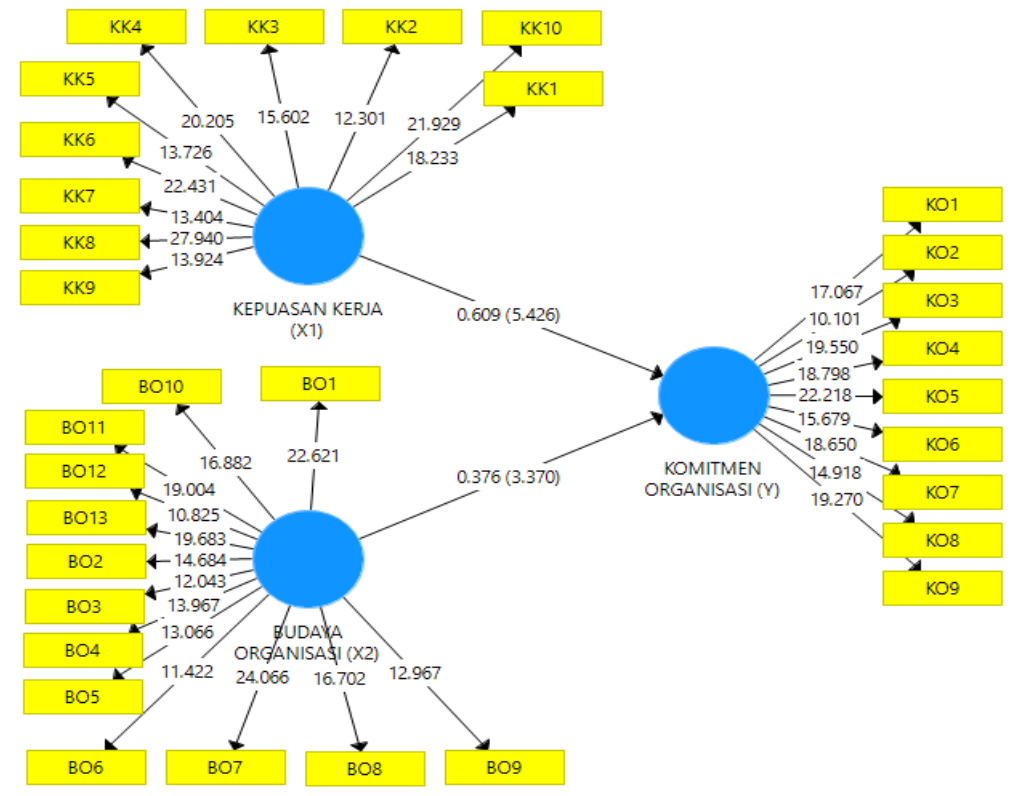

Gambar 3. Output smartPLS hasil bootstraping

Sumber: Hasil pengolahan smartPLS (2020)

Tabel 2. Hasil pengujian hipotesis

\begin{tabular}{cccccc}
\hline & Hipotesis & $\begin{array}{c}\text { Original } \\
\text { Sample }\end{array}$ & $\begin{array}{c}\mathrm{T} \\
\text { statistics }\end{array}$ & P values & Kesimpulan \\
\hline $\mathrm{H} 1$ & $\begin{array}{c}\text { Kepuasan Kerja } \rightarrow \\
\text { Komitmen Organisasi }\end{array}$ & 0,609 & 5,426 & 0,000 & Tidak ditolak \\
\hline $\mathrm{H} 2$ & $\begin{array}{c}\text { Budaya Organisasi } \rightarrow \\
\text { Komitmen Organisasi }\end{array}$ & 0,376 & 3,370 & 0,000 & Tidak ditolak \\
\hline
\end{tabular}

Sumber: Hasil pengolahan smartPLS (2020)

Dari hasil uji hipotesis pertama, terlihat bahwa kepuasan kerja berpengaruh positif pada komitmen organisasi, yang ditunjukkan oleh nilai original sample 0,609>0, nilai t-statistik sebesar 5,426 > 1,645 , dan $p$-value sebesar $0,000<0,05$. Hasil penelitian ini sesuai dengan hasil penelitian Jalees \& Ghauri (2016) yang menemukan bahwa kepuasan kerja secara positif memengaruhi komitmen organisasi karyawan universitas swasta di Pakistan. Lalu, sejalan dengan hasil penelitian Daniel \& Purwanti (2015) yang menemukan bahwa kepuasan kerja yang terus meningkat akan menghasilkan komitmen organisasi yang semakin kuat pada karyawan universitas swasta di Tangerang. Hasil penelitian ini juga sejalan dengan hasil penelitian ElKordy (2013) yang menyatakan bahwa terdapat pengaruh positif signifikan kepuasan kerja terhadap komitmen organisasi karyawan eksekutif yang terdaftar dalam program EMBA (Executive Master of Business Administration). Dengan demikian, hipotesis yang dirumuskan secara keseluruhan tidak ditolak, baik secara statistik maupun secara teoritis.

Kepuasan kerja mengacu pada peristiwa emosional karyawan sehari-hari terhadap situasi pekerjaan yang dihadapi yang mana berpengaruh terhadap komitmen organisasi karyawan, karena karyawan yang merasa puas akan memertahankan keanggotaannya di dalam organisasi (Supeli \& Creed, 2016). Kepuasan kerja mengacu pada sikap positif para karyawan terhadap pekerjaan mereka yang diungkapkan berdasarkan evaluasi karyawan pada situasi pekerjaan mereka saat ini, yang mana karyawan yang merasa puas cenderung beradaptasi dengan baik pada kondisi kerja dibandingkan yang tidak puas, sehingga membuat karyawan menyatukan dirinya dengan kondisi kerja di perusahaan dan 
memilih untuk memertahankan keanggotaan mereka serta meningkatkan loyalitas mereka pada perusahaan.

Dari hasil uji hipotesis kedua, terlihat bahwa budaya organisasi berpengaruh positif terhadap komitmen organisasi karyawan, yang ditunjukkan oleh nilai original sample 0,376>0, nilai t-statistik sebesar 3,370 > 1,645, dan $p$-value sebesar $0,000<0,05$. Hasil penelitian ini sejalan dengan hasil penelitian yang dikemukakan oleh Jalees \& Ghauri (2016) bahwa ada pengaruh yang positif dari budaya organisasi terhadap komitmen organisasi karyawan yang bekerja pada universitas swasta di Pakistan. Lalu, sejalan juga dengan hasil penelitian ElKordy (2013) yang mengemukakan adanya pengaruh yang positif dari budaya organisasi terhadap komitmen organisasi karyawan eksekutif yang terdaftar dalam program EMBA (Executive Master of Business Administration) dan karyawan lulusan fakultas perdagangan. Hasil penelitian ini sejalan juga dengan hasil penelitian Kawiana dkk. (2018) yang mengemukakan bahwa terdapat pengaruh budaya organisasi secara positif terhadap komitmen organisasi karyawan Bank Perkreditan Rakyat (BPR) di Bali. Budaya organisasi yang kuat berpengaruh terhadap organizational outcomes, seperti: kinerja yang baik, perilaku organisasi karyawan positif, kontrak psikologis antar kolega yang baik, serta tingkat absensi yang minim (Firuzjaeyan et al., 2015), sehingga disimpulkan bahwa budaya organisasi mengacu pada nilai-nilai dan norma yang dibentuk perusahaan yang mana jika karyawan merasa cocok dengan nilai dan norma tersebut, maka mereka akan lebih melibatkan dirinya dalam organisasi serta memertahankan keanggotaannya dalam organisasi tersebut.

\section{SIMPULAN DAN SARAN}

Kesimpulan dalam penelitian ini adalah kepuasan kerja berpengaruh positif pada komitmen organisasi karyawan dan budaya organisasi berpengaruh positif pada komitmen organisasi karyawan. Jika karyawan merasa puas terhadap pekerjaannya, maka karyawan tersebut cenderung akan memertahankan keanggotaannya dalam perusahaan, sebaliknya jika merasa tidak puas, maka karyawan tersebut kemungkinan tidak akan bertahan dalam perusahaan, bahkan memilih untuk keluar dari perusahaan. Hal tersebut tentunya akan meningkatkan turnover karyawan. Demikian pula, jika karyawan merasa cocok dengan nilai dan norma yang terdapat dalam budaya organisasi tersebut, maka mereka akan lebih melibatkan dirinya dalam organisasi serta memertahankan keanggotaannya dalam organisasi tersebut.

Keterbatasan dalam penelitian ini adalah variabel yang digunakan sebagai anteseden komitmen organisasi hanya dua, yakni: kepuasan kerja dan budaya organisasi. Kemudian, fenomena latar belakang hanya menggunakan hasil survei dan beberapa penelitian terdahulu. Lebih dari itu, penelitian ini hanya menggunakan populasi pada salah satu perusahaan saja, sampel yang digunakan hanya 50 orang, serta kuesioner riset hanya disebarkan secara online.

Saran bagi peneliti selanjutnya untuk menambah variabel independen baru, menggunakan data-data yang lebih terperinci dalam mengkaji fenomena, serta menggunakan objek penelitian lebih dari satu perusahaan agar hasil penelitian konsisten dan dapat digeneralisasikan. Bagi perusahan, disarankan untuk meningkatkan kepuasan kerja dan budaya organisasi para karyawannya yang dapat mengakibatkan peningkatan komitmen organisasi mereka. Perusahaan diharapkan meningkatkan gaji yang diberikan kepada karyawannya dan memertahankan sistem penempatan kerja karyawan sesuai dengan keahliannya. Dari sisi budaya organisasi, perusahaan disarankan untuk berfokus pada pencapaian dan tujuan, serta memertahankan tingkat efisiensi perusahaan. Dari sisi komitmen organisasi, perusahaan disarankan untuk meningkatkan faktor kesetiaan karyawan. Dari segi emosi, sosial, dan ekonomi, sebaiknya perusahaan melakukan berbagai daya upaya dalam lingkup pekerjaan dan organisasi, sehingga dapat memertahankan kepuasan setiap karyawannya. 


\section{REFERENSI}

Azadi, A., Farsani, S. B., Farsani, M. E., \& Aroufzad, S. (2013). Relationship between organizational culture and organizational commitment among woman physical education teachers. European Journal of Experimental Biology, 3(1), 531-535.

Belias, D., \& Koustelios, A. (2014). Organizational culture and job satisfaction: A review. International Review of Management and Marketing, 4(2), 132-149. Diperoleh dari https://www.econjournals.com/index.php/irmm/article/view/746/pdf.

Daniel, F., \& Purwanti, A. (2015). The impact of organizational culture and job satisfaction to organizational commitment and employees' job performance (An empirical study at a University in Tangerang). Asia-Pacific Management Accounting Association (APMAA) Annual Conference, 1-18. DOI: 10.13140/RG.2.1.1196.4240.

ElKordy, M. (2013). Transformational leadership and organizational culture as predictors of employees attitudinal outcomes. Business Management Dynamics, 3(5), 15-26. Diperoleh dari http://www.bmdynamics.com/issue_pdf/bmd110426-\%2015-26.pdf.

Fauzia, M. (2020, Januari 23). LinkedIn: work life balance kunci kepuasan bekerja. Diperoleh dari https://money.kompas.com/read/2020/01/23/121200826/linkedin--work-life-balance-kuncikepuasan-bekerja.

Firuzjaeyan, A. A., Firuzjaeyan, M., \& Sadeghi, B. (2015). A survey of the effect of organizational culture on organizational commitment based on Allen and Meyer model (Case study: high school teachers of Bandpey region). International Journal of Academic Research in Business and Social Sciences, 5(1), 1-9. DOI: 10.6007/IJARBSS/v5-i1/1394.

Garson, D. (2016). Partial least squares: Regression and structural equation models. Asheboro, North Country: Statistical Associates Publishers.

Ghozali, I., \& Latan, H. (2015). Partial least squares: Konsep, teknik dan aplikasi menggunakan SmartPLS 3.0. Edisi 2. Semarang: Badan Penerbit Universitas Diponegoro.

Hock, C., \& Ringle, C. M. (2006). Management of multi-purpose stadiums: Importance and performance measurement of service interfaces. International Journal of Services Technology and Management, 14(2), 188-207. DOI: 10.1504/IJSTM.2010.034327.

Jalees, T., \& Ghauri, S. (2016). Influence of organizational culture on job satisfaction, organizational commitment and turnover intention: A study on a Pakistani Private University. Market Forces, 11(1). 11-26. Diperoleh dari: http://www.pafkiet.edu.pk/marketforces/index.php/marketforces/article/view/309.

Kawiana, I. G. P., Dewi, L. K. C., Martini, L. K. B., \& Suardana, I. B. R. (2018). The influence of organizational culture, employee satisfaction, personality, and organizational commitment towards employee performance. International Research Journal of Management, IT and Social Sciences, 5(3), 35-45. https://doi.org/10.21744/irjmis.v5i3.666.

Prerana. (2017). Effect of employee engagement on organisational commitment. Indian Journal of Commerce and Management Studies, 8(2), 101-108. DOI: 10.18843/IJCMS/V8I2/14.

Robbins, S. P., \& Judge, T. A. (2015). Perilaku organisasi. Edisi Keduabelas. Jakarta: Salemba Empat.

Schein, E. H. (2009). Organizational culture and leadership. 4th Edition. San Fransisco: John Wiley $\&$ Sons.

Sekaran, U., \& Bougie, R. (2013). Research methods for business: A skill building approach. 5th Edition. New York: John Wiley \& Sons.

Sugiyono. (2016). Metode penelitian kuantitatif kualitatif dan kombinasi (mixed methods). Bandung: Alfabeta.

Supeli, A., \& Creed, P. A. (2016). The longitudinal relationship between protean career orientation and job satisfaction, organizational commitment, and intention to quit. Journal of Career Development, 43(1), 66-80. DOI: 10.1177/0894845315581686.

Umam, K. (2010). Perilaku organisasi. Bandung: CV Pustaka Setia.

Vizano, N. A., Setiyani, A., \& Nawangsari, L. (2018). The effect of organizational culture \& job satisfaction on turnover intention, with organizational commitment as a mediating variable 
Jurnal Manajemen Maranatha a Vol. 20 Nomor 1, November (2020)

(Study case at PT Sas Kreasindo Utama). Journal of Economics, 23(1), 99-113. DOI: 10.24912/je.v23i1.3.

Yanti, S., \& Dahlan, J. A. (2017). The effects of organizational culture, leadership behavior, and job satisfaction on employee organizational commitment. Journal of Positive Management, 8(4), 80-96. DOI: 10.1108/02621710410529785. 
Jurnal Manajemen Maranatha — Vol. 20 Nomor 1, November (2020) 